\title{
Innovations for Improving Access to Quality Health Care: The Prospects for Municipal Health Insurance in Guatemala
}

\author{
Gary Bland, Lucrecia Peinado, and Christin Stewart
}

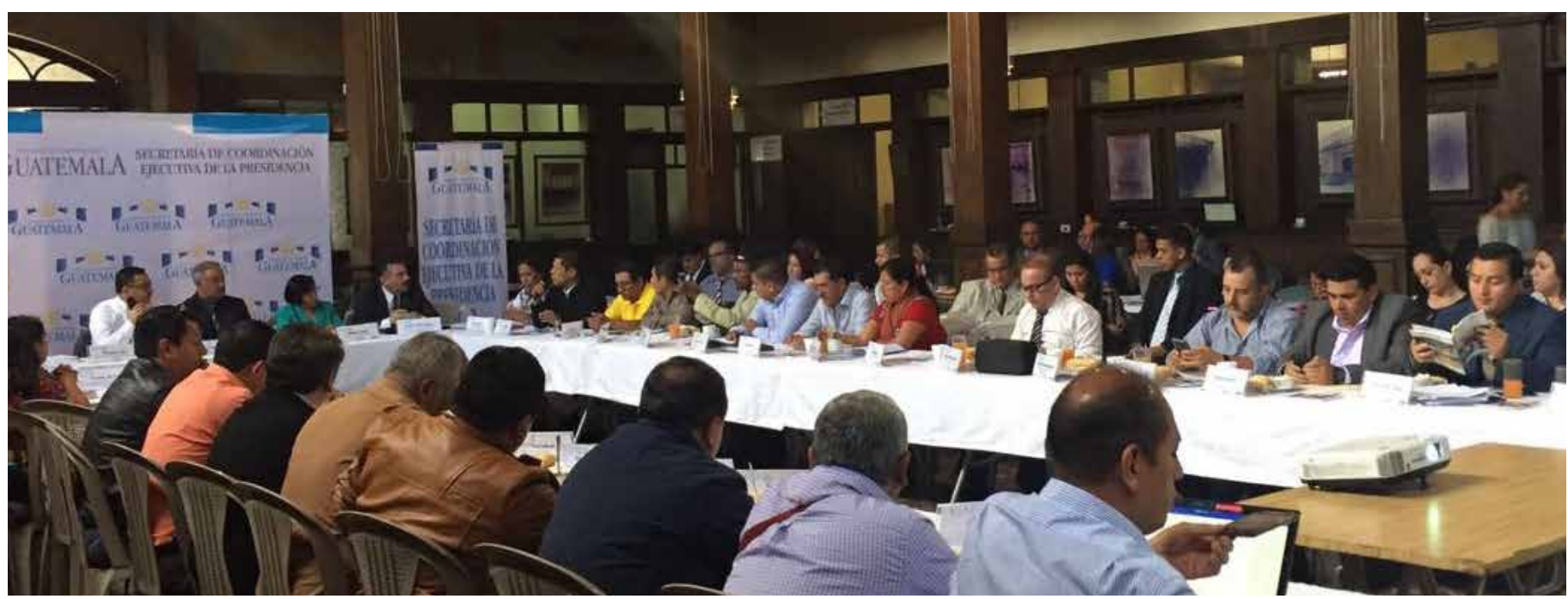

Despite being guaranteed heath care by the country's constitution, in Guatemala, one-third of the population lacks access to health services and increasingly must pay for necessary care out of pocket. In rural and indigenous areas especially, access to and quality of health services are poor. ${ }^{1}$ Existing health insurance coverage is so limited and fragmented that out-of-pocket costs now constitute more than half of total health financing. ${ }^{2}$ Given the severe challenges facing Guatemala's system of health care, the search for solutions is urgent for both concerned policymakers and practitioners. One recently proposed innovation is municipal insurance, which has not yet been attempted and which may-or may not-provide an avenue for financial protection against rising costs and improved access to quality care.

\section{Key Policy Recommendations}

- Given the complexity of municipal insurance schemes, collaboration among the relevant municipalities and governing national agencies is especially important during the design phase.

- Municipal capacity, financial constraints, and the potential deepening of inequities that can occur must be given serious consideration in any scheme.

- Municipal insurance is an idea worth exploring in full recognition of the challenges involved. A pilot approach is warranted.

- Municipal insurance schemes should ideally be considered within a broader framework of health-sector decentralization, given that the two are interrelated. Thus, it is important that the National Decentralization Agenda, approved in early September 2017, is set for implementation. 
Municipal insurance is best described as a collective compact in which the municipal government is a lead actor in designing, risk pooling, allocating, purchasing, and supervising a health care financing arrangement-an insurance policyto provide health services to residents of a municipality. Participation is defined by geographic location-residency in the municipality-and is usually treated as voluntary. Like health financing arrangements generally, municipal health insurance promises to provide financial protection against the impoverishing effects of illness, support sustainable access to health care, and reduce social exclusion. ${ }^{3}$

This brief presents a political economy analysis of the prospects for adopting municipal insurance in Guatemala. The analysis was conducted in the belief that the pursuit of reform is at least as much a political question as a matter of technical considerations. The analysis is primarily based on key informant interviews with nearly 30 of the principal actors in national health policy, local government, health administration, international aid agencies, public and private insurance sectors, and nongovernmental organizations. ${ }^{*}$ We sought to determine, by identifying political opportunities and constraints on reform, the feasibility of implementing municipal insurance. A better understanding of the political economy of municipal insurance will allow reformers to better determine if, when, and how the pursuit of such schemes-and related reforms, such as health sector decentralization-can be successful.

Municipalities in Guatemala are formally accorded autonomy and a broad mandate under the constitution and laws. Thus, they can provide services that "improve the quality of life of the inhabitants," including "preventive health" services. ${ }^{\dagger}$ Several municipalities currently provide health services to varying degrees, and there are examples of insurance providers designing innovative packages for targeted groups of beneficiaries. Legally, municipal insurance is a feasible proposition. There seems to be little doubt that at least some municipalities or a grouping of them-whether the wealthiest, most progressive, or better managed-could collaborate with the relevant national agencies to devise and institute a workable municipal insurance scheme.

* Interviews were conducted by the authors in February 2017. All interview participants were accorded anonymity.

$\dagger$ See the Guatemala Constitution, article 257; Health Code Decree No. 90-97; General Decentralization Law No. 14-2002; and Municipal Code Decree No. 12-2002.

\section{One Example of a Municipal Health Insurance Scheme}

In 2015, the Guatemalan municipality of Villa Nueva-a large (pop. 710,218), suburban, and relatively wealthy municipality located south of Guatemala City-designed a model for establishing so-called "municipal health insurance." Municipal insurance of any kind had not been tried previously in Guatemala. The goal was to create a sustainable costrecovery mechanism for the health services provided by the municipality. Existing and upgraded infrastructure and services would be used to create a primary health care package for municipal residents, who would access services through a collective health insurance policy. Community leaders hired by the municipality would offer the nonobligatory, low-cost policy to Villa Nueva residents-ideally generating a sufficiently large pool of beneficiaries-and a contracted insurance provider would reimburse the municipality at pre-established rates. Services would include ambulances, a medical emergency center, X-rays, general medicine, gynecology, ophthalmology, laboratory testing, mammography, and a call center.

The Villa Nueva public health company (Empresa Municipal de Salud, or EMUS), which was to be established to operate the system, planned to generate additional revenue by keeping service costs low. Villa Nueva officials also saw EMUS as an opportunity to generate income by offering services for insurance reimbursement under the systems operated by the Ministry of Public Health and Social Assistance (MSPAS) and the Guatemalan Social Security Institute (IGSS). Ultimately, Villa Nueva was unable to secure the necessary authorization from the Ministry of Finance and from the national Comptroller General to proceed. Though seen as technically and budgetarily feasible, the scheme was considered a profitmaking endeavor that violated Guatemala's legal prohibition on charging fees to users of public health care services. The scheme also faced criticism that it was developed without the collaboration of or input from MSPAS. Villa Nueva, as of this writing, continues to pursue the scheme, but making it a reality has proven difficult, and new models will likely need to be considered.

\section{Potential Obstacles to Municipal Insurance Reform}

Municipal insurance lacks a constituency of support at present. As interviews indicated, municipal insurance is a new and not well-known reform idea. Currently, beyond the Villa Nueva experience, there is no single proposal or model of municipal insurance to scrutinize or debate. Municipal insurance could be included in a reform aimed at decentralizing health care services, which is a politically fraught topic of its own. It remains to be seen whether the idea or a particular scheme becomes more widely accepted. 
To make progress, MSPAS support for municipal insurance schemes, or for broader decentralization of health services that can support them, must be consistent. As reflected in interviews, MSPAS supported neither the idea of municipal insurance nor decentralization until very recently. MSPAS's argument was that such schemes amount to bringing private, profit-making insurance providers-privatization-into the realm of public health care. The schemes do not increase access to care, the argument was, because most Guatemalans would not be able to afford the insurance packages. ${ }^{4}$

In September 2017, amid a political crisis, the MSPAS minister resigned. The new ministry, which has publicly expressed support for implementation of the new National Decentralization Agenda, is much more favorably inclined toward decentralization and related reforms. Any advocate of municipal insurance would rightly see this as a favorable development-not an obstacle. Turnover of ministerial leadership, however, has long been an issue, and it raises concern about the continuity of any reform effort.

Well-known concerns about the effects of decentralization will surely be cited in opposition to such schemes. The capacity of many municipalities is weak, authorities are often seen as corrupt, and heavy clientelism leads to wasteful, misdirected investment that is not in the public interest. Respondents concerned with overseeing municipal financial management, in particular, addressed these points. These concerns may be overstated, but municipal insurance could exacerbate the problems, especially because it may involve the management of large insurance funds. $\neq$

The perception that an insurance scheme might increase inequity can produce a powerful political argument against it. In rural areas where services are poor, large numbers of Guatemalans do not have access to care. With the possible exceptions of coverage for catastrophic health care and publicly financed primary health care at the community level, it is not clear that municipal insurance can deliver assistance that will help.

As noted previously, municipal insurance is viewed as feasible for urban municipalities with heavy formal employment, where large risk pools can be generated to ensure financial sustainability or profitability. Municipal insurance may therefore benefit mostly heavily urban populations that already have huge advantages, although cities also have higher incidences of traffic accidents, violence-related injuries, obesity,

* Note that Guatemalan law requires municipalities seeking delegation of a new responsibility to demonstrate solvency, sustainability, and transparency and to prove that the central government does not already provide the service. and chronic disease. There is a significant gap in the density of health workers (doctors, nurses, and midwives) between urban (25.7 per 10,000 inhabitants) and rural (3.0) areas, where there is also a scarcity of workers who speak local languages. 5 The poor state of public health infrastructure, particularly in rural areas, has not changed substantially in decades. In addition, limited-coverage packages can leave the insured without critical services, and deep poverty in rural areas severely limits residents' ability to pay insurance premiums.

Enforcement of a regulatory framework for health care, notably the standardization of care and the monitoring of its quality, is poor in Guatemala. According to some respondents, ensuring the provision of quality services for the insured may be impossible. Even assuming that a relatively small, rural municipality is able to find the means to deliver health care, residents may prove unwilling to pay a premium because they lack confidence that quality care will be available should they later become ill.

Municipal governments' ability to finance municipal insurance is limited. Depending on the model, administrative costs, potential subsidies, and any new services will need to be covered by municipalities. Several respondents raised concerns about the source of financing, municipal capacity to pay, and appropriate use of the budget for insurance. Moreover, many municipalities' strong dependence on the national government's fiscal transfers may leave them with little financial space within which to maneuver.

To the extent that municipal insurance schemes are perceived to contravene deep-seated values such as favoring cost-free public health care and opposing the use of private-sector outsourcing, support for municipal insurance is likely to suffer. $\S$ Key respondents faulted the municipality of Villa Nueva's attempt to use insurance to help recover costs and garner revenue to sustain EMUS. The use of municipal insurance in a way that suggests the commercialization of public health care provision was widely considered politically untenable. The notion that public health care is a right and therefore should be free is drawn from the Constitution and is explicitly stated in the health code. ${ }^{* *}$ Because this notion is

$\$$ Apparently, these principles do not apply to IGSS, which provides prepaid insurance and outsources for services. However, contributions to IGSS insurance are obligatory and are considered tax income (payroll tax), not payment for services. Both IGSS and MSPAS have within their respective regulations the authority to contract for services as needs require.

** The National Health Code was reformed in 2003 to state that MSPAS and all other public institutions must ensure that health services are provided free of charge. The provision is seen as limiting the ability of the public sector to generate revenue from people's contributions for health services. Most respondents interpreted this provision as restricting the costs of premiums for health insurance, especially if the insurance is mandatory. 
so deeply embedded in Guatemalan political culture, there are strong objections to outsourcing public health care to turn a profit.

Municipal insurance can be viewed as contributing to the further fragmentation of the Guatemalan health care system. One of the major obstacles to health financing reform is "the coexistence of different health subsystems with different financing modalities addressed to different population strata. These services are differentiated by payment capacity, economic position, social class, and labor market insertion."2 Some respondents argued that municipal insurance schemes would simply add to the fragmentation and that municipal efforts would be better placed focusing on local health improvements in water and sanitation, the environment, and similar areas.

Laws and regulations related to auditing municipal finances are subject to interpretation and strict enforcement, often leaving municipalities worried or fearful of being cited for violations. Inconsistent interpretation can paralyze municipal activity. Interviewees confirmed that interpretations can differ among institutions and within a single institution (e.g., the Comptroller General) around the role of municipalities in an activity like health insurance. Inter-institutional collaboration would help address this concern.

\section{Factors Favoring Municipal Insurance Reform}

After a 15-year hiatus, decentralization has returned to the policy reform agenda in Guatemala with the Morales administration's promulgation in September 2017 of the National Decentralization Agenda. The Agenda establishes a formal process for municipalities to request, get certified, and the be accredited to receive new functions in health, among other sectors. The reform process is being led by the Secretary of Executive Coordination of the Presidency and is supported by a multiple agencies and stakeholders, including MSPAS, the Secretary of Planning and Programming of the Presidency, Ministry of Finance, National Association of Municipalities, and the National Urban and Rural Development Council. The next step is to begin the decentralization of health functions through a series of pilot municipalities. Interview respondents pointed out that a strong presidential directive such as the Agenda can quickly lead to movement in health or any other sector deemed a priority. This is good news for anyone interested in having municipalities take on new health care responsibilities.

Even considering longstanding obstacles to decentralization, most respondents felt that municipalities have sufficient authority to institute municipal insurance. As explained below, key respondents reported that what matters most is not the level of municipal authority but, rather, the process through which an insurance scheme is designed and implemented.

Municipalities' constitutionally protected autonomy and their legally delineated role in public service provision are central to the notion of municipal insurance. However, most municipalities do not have the institutional and financial capacity to develop and sustain a municipal insurance program. Urban, high-income governments with a large base of formal employment are considered the best candidates. The idea of all municipalities participating to create a large risk pool-perhaps under the auspices of the National Association of Municipalities, the current president of which is the mayor of Villa Nueva-has also been put forward as well.

Several key actors indicated that municipal insurance is feasible if done in a collaborative and transparent fashion that respects planning, budgetary, and other regulatory requirements. These respondents often mentioned using a formal agreement (or convenio) with the ente rector, or governing authority (usually meaning MSPAS), for the coordinated development of municipal provision of a new service.

Municipalities are independently engaged in health infrastructure and the provision of primary health care services; none has ever been involved in providing health insurance. However, most respondents considered health care-insurance in particular-a delegated or shared function. In the absence of a national directive, individual municipalities must develop a convenio to take on the new responsibility. Such agreements are not easily reached and implemented. Strategic cooperation with IGSS, which is presently under pressure to expand coverage to ensure its operation, is also a potential entry point for municipal health insurance schemes. ${ }^{\dagger \dagger}$

In addition, municipal insurance is highly technical and involves a variety of stakeholders ranging from civil society to multiple agencies of the central government. In practical terms, municipal insurance is unlikely to be done successfully in the absence of buy-in generated through collaboration. Guatemalans cite the transfer of the property tax to municipalities as an example - albeit a rare one - of a nationwide decentralization initiative. One can also find various examples of existing convenios for the coordinated delivery of public services, in which the municipality presently contributes land and infrastructure, for example, while the ministry provides the required personnel.

\footnotetext{
$\dagger$ Implementation of any new social security scheme cannot duplicate IGSS services and must be authorized by IGSS.
} 
Advocates for municipal autonomy promote decentralization and naturally appear more likely to support the idea of municipal insurance. The failures of the health care system are seen by these advocates in part as a failure to implement decentralization to strengthen democratic accountability for the provision of critical social services at the municipal level. Indeed, the state has fallen far short of its constitutionally mandated obligation to ensure the health and social welfare of all Guatemalans. This is, in part, the rationale for decentralization, which has yet to occur in the health sector.

When viewed as part of a broader initiative for decentralization of health care services, the argument for municipal insurance becomes stronger. Decentralization is controversial, however, and its proponents-municipalities, community empowerment organizations, and state reformers, among others-are typically arrayed against an equally powerful group of opponents, notably the line ministries who fear a loss of power and labor unions concerned about job security. According to interview respondents, much of the same can be expected of any debate over municipal insurance.

An increase in municipalities' own-source revenue of nontax origin could be used to invest in health insurance premiums for those who cannot afford them and to support the administrative costs of an insurance scheme. Unlike taxes, which must be defined by the national congress, municipal fees and charges can be legally established by the municipal council. 6 With encouragement and technical assistance, municipalities can take better advantage of their authority to establish fees and improve their revenue collection efforts.

Municipal financial information systems and support are available, if not required, to assist in financial reporting, fiscal oversight, and transparency in the design and implementation of municipal insurance schemes. For example, the online Integrated Accounting System for Municipal Governments is reportedly prepared to provide financial systems support for municipal insurance implementation. In addition, the national Comptroller General is prepared to monitor the preparation of any insurance scheme and accompany its implementation through concurrent audits.

In Guatemala, the development of creative insurance products tailored to a particular population and coverage needs is a feasible proposition. Any new insurance product must come from an authorized insurance company and then must be approved by the Superintendent of Banks. Innovative insurance products can be developed. For example, Banrural (Guatemala's rural bank) provides low-cost, collective insurance for women age 18-84, which offers preventive consultations and screenings and limited treatment of common cancers. The monthly premium for this insurance is
$\$ 4$. If cancer is diagnosed, the policy provides about $\$ 4,000$ in compensation. Banrural also has health care plans for workers and their families and mixed products for students. College students can obtain coverage against personal accidents for $\$ 1.50$ per month. Cooperatives also offer a wide array of health care plans for children, families, and elderly people.

\section{Policy Implications}

The institution of municipal insurance requires a comprehensive, collaborative intergovernmental approach. Proposed schemes must consider designs that can significantly improve health care coverage, health financing, and financial protection, while carefully considering Guatemala's developmental challenges. Advocates should focus on how to design a consensus-based system to address the health care crisis in an equitable-or inequity-reducing-fashion. The objectives, expected advantages, and potential negative effects of any scheme should be made as clear as possible.

Given the complexities, a pilot approach should be considered before moving to scale. A variety of options should be considered, including schemes for a single municipality, designs involving groups of municipalities (perhaps mancomunidades), a nationwide plan through an institution such as National Association of Municipalities, and the possibility of cooperating with IGSS, which is the lead authority with respect to health insurance. The support and sustained involvement of MSPAS is obviously important. Collaboration around a convenio could become more of a possibility as the national government moves forward with its decentralization agenda.

Health insurance products (and other insurance-related operations) will have to be developed with one of Guatemala's authorized insurance companies. Another, more ambitious option is the creation of a new insurance company for this purpose, fully authorized and supervised by the Superintendent of Banks and fully recognizing the pitfalls associated with the expectation that public health care should be free of charge and not a profit-making enterprise.

Public perceptions about gratuity, outsourcing, and commercialized health care must be carefully managed to develop a solid political consensus around any municipal insurance scheme. Advocates should attempt to identify how the pursuit of an effective municipal insurance program can support or be part of a larger program for achieving health decentralization. The design of such a policy should avoid adding to the existing fragmentation of the health system, including the social security system under IGSS. Any plan must coexist with MSPAS, IGSS, and private insurance operations, ideally in a fully complementary fashion. 


\section{References}

1. Pena CL. Improving access to health care services through the Expansion of Coverage Program (PEC): the case of Guatemala. UNICO Studies Series 19. Washington (DC): World Bank; 2013.

2. Ministerio de Salud Pública y Asistencia Social (MSPAS). Cuentas nacionales de salud: financiamento de la salud en Guatemala periódo 1995-2014. Guatemala City (Guatemala): MSPAS; 2015.

3. Preker S, Lindner M, Chernichovsky D, Shellenkens O, editors. Scaling up affordable health insurance: Staying the course. Washington (DC): World Bank; 2013. https://doi. org/10.1596/978-0-8213-8250-9

4. Hernández OJ. Salud Pública, el Enfermo Crónico al que la Ministra Intenta Rescatar. Plaza Pública; c2016 [cited 13 Dec 2017]. Available from: https://www.plazapublica.com. $\mathrm{gt} /$ content/salud-publica-el-enfermo-cronico-al-que-laministra-intenta-rescatar

5. Abt Associates, Inc. Guatemala health system assessment. Bethesda (MD): Health Finance and Governance Project, Abt Associates; 2015.

6. Bonet J, Rueda F. Esfuerzo fiscal municipal en Guatemala. Technical Note IDB-TN-513. Washington (DC): InterAmerican Development Bank; 2013

\begin{abstract}
About the Authors
Gary Bland, PhD, is a Fellow in Governance at RTI International.

Lucrecia Peinado, MD, is a public health consultant.

Christin Stewart, MPH, is a health systems specialist at RTI International..

\section{Acknowledgments}

The authors thank Thomas Fagan and the HEP+ Guatemala staff-particularly Ricardo Valladares, José Eduardo Silva, Albertico Orrego, Herminia Reyes, and Iliana Palomo_for their important contributions to this brief.

This policy brief is an abridged and updated version of a Health and Education Policy Plus (HEP+) project policy brief written by the same authors for HEP+. HEP+ is financed by the US Agency for International Development (USAID) and is being implemented by Palladium with support from RTI International (RTI). The HEP+ brief may be found at: http://www.healthpolicyplus.com/pubs. $\mathrm{cfm}$ ?get $=7148$. Adapted with permission.
\end{abstract}

RTI Press Research Briefs and Policy Briefs are scholarly essays on policy, methods, or other topics relevant to RTI areas of research or technical focus.

RTI International, 3040 East Cornwallis Road, PO Box 12194

Research Triangle Park, NC 27709-2194 USA

+1.919.541.6000_rtipress@rti.org_www.rti.org

C2017 RTI International. RTI International is a registered trademark and a trade name of Research Triangle Institute. The RTI logo is a registered trademark of Research Triangle Institute.

(c) $(-)$ This work is distributed under the terms of a Creative Commons Ay NC ND Attribution-NonCommercial-NoDerivatives 4.0 license (CC BY-NC-ND), a copy of which is available at https://creativecommons.org/ licenses/by-nc-nd/4.0/legalcode.

www.rti.org/rtipress. 